\title{
Journal of Education
}

\section{ISSN Online: 2616-8383}

Parental Divorce and Children's Educational Attainment in United States of America

Coleman Rodolfo Galluzzo, Bastaits Goodman Lansford \& Halford Waggoner 


\title{
Parental Divorce and Children's Educational Attainment in United States of America
}

\author{
1*Coleman Rodolfo Galluzzo, ${ }^{2}$ Bastaits Goodman Lansford \& ${ }^{3}$ Halford Waggoner \\ 1,2,3 University of Virginia
}

*Email of the corresponding author: colodolfoGalluzzo@gmail.com

How to cite this article: Galluzzo, C., R., Lansford, B., G., \& Waggoner, H. (2021 Parental Divorce and Children's Educational Attainment in United States of America. Journal of Education, 4(8), 11-19. https://doi.org/10.53819/81018102t5033

\begin{abstract}
Divorce frequently contributes to depression, anxiety or substance abuse in one or both parents and may bring about difficulties in balancing work and child rearing. These problems can impair a parent's ability to offer children stability and love when they are most in need. Thus, the study sought to examine effect of parental divorce on children's educational attainment in united states of America. The study was a literature-based review. The inferences of the study were based on the previous findings from the existing literature. The study findings indicated that parental divorce affect the children's educational attainment in united states of America negatively. Divorce and separation correlate positively with diminished school achievement and performance. Children whose parents are separated go through a wide range of feelings, occasionally those can show up in some common disruptions in their life. The common effects of separation on children consist of schooling troubles, such as bad performance, behavior issues at school, defiance and noncompliance, depression, problem forming intimate partnerships, boosted anxiety and sadness/ anger. The research found out that divorce permanently damages the household and the relationship between children and parents. Divorces that entail heavy adult conflict are generally the ones which affect children more adversely. The research concluded that adult separation/divorce is connected with increased threat for numerous emotional, academic and social issues throughout the life-course. The study recommended that divorce should be discouraged specially to couples with children. In case the divorce is the only way to go, the parents need to develop mechanism that will enable the children to continue with a normal life.
\end{abstract}

Keywords: Parental Divorce, Children's Educational Attainment, United States of America

https://doi.org/10.53819/81018102t5033 


\subsection{Background of the Study}

There are more than 2,000,000 marriage relationships annually in the United States. That's a lovely act 4,000,000 individuals a year devoting the rest of their lives to one another (Waggoner, 2019). Most of those will last forever. However, concerning 875,000 which is $43.5 \%$ will certainly end in separation at some point. While separation might be the most effective decision for these failed marriages over time, the temporary effects can be devastating to everybody included. Mostly it's the children that really feel the trauma. All children react in different ways to separation of their parents; however, psychologists have actually discovered that children also react in a different way according to age. Young children typically experience sorrow when they discover that their parents are divorcing and become sad and clingy. Children, usually view separation as dishonesty and retreat from their parents (Bryner, 2021). After the death of a parent, divorce is the other most traumatic issue in a child's life. And yet, for numerous factors, divorce prevails in the USA. According to the American Psychological Association, concerning 40 to 50 percent of marriages in the U.S. end in separation (Sanders, Halford \& Behrens, 2018). For those couples that have children, that shows, necessarily, that their youngsters will, or have already, experience a stressful event.

Unfortunately, researches have actually shown that children who experience parents' separation can be impacted well into adulthood. Children of divorced parents can experience self-protective fear and an unwillingness to become part of a fully committed relationship (Rohrbaugh, 2020). Many reports having trust concerns. These problems can bring about other behavioral issues, which can threaten their own relationships like: A tendency to be overly mindful in relationships, a propensity to maintain partnerships shallow to prevent commitment, manipulative behavior to keep the other partner devoted to the partnership and readiness to surrender on the partnership as soon as troubles arise. When parents' divorce, it can be tough for the entire household (Zartler, 2019). It can be specifically challenging on children that have to handle an upheaval of their lives and be used to the brand-new fact of their day-to-day living. For children, separation is specifically challenging. Given that teens are extra qualified and independent, parents in some cases lean on them to help out with more youthful siblings or take care of more duties. Some parents also inappropriately vent to them or count them to be messengers in between them and their other parent. Despite the fact that children may be more psychologically savvy than their younger siblings, they are still not adult peers. They require assistance from their parents and to discover just how to adapt after a separation, too. Teens are most likely to handle the results of separation by taking part in high-risk actions (Seeman, 2018). Substance abuse and very early sex are extra typical amongst children of divorce than their peers.

The level of dispute prior to and after separation also affects whether or not the children will certainly encounter lengthy or temporary mental illness (Goodman, Bonds, Sandler \& Braver, 2019). Separation is seldom friendly, peaceful, and worry-free. Usually, it's an untidy, difficult struggle between 2 parents that remain in high dispute. Children, caught between, experience this conflict throughout the divorce process. According to many studies, it's the hefty problem itself greater than the technological, legal process of separation that triggers youngsters of separation to be impacted so strongly. That's why separations that entail hefty adult problem are generally the ones that affect children most negatively (Mechanic and Hansell, 2021). Teens staying with intact family members with more dispute had lower degrees of wellbeing than those staying in families

\section{https://doi.org/10.53819/81018102t5033}


of separation with reduced dispute, because separations which entail heavy amounts of parental problem are normally the ones that affect children most adversely, we can recognize the reverse holds true also: youngsters often tend to fare better when the separation is as smooth as possible, and does not involve high levels of anxiety in between the spouses.

One problem that negatively affects teen little girls after divorce is daddy lack. Father absence places teen children at specific risk for very early sex and adolescent maternity. Children of separated parents are very prone to daddy lack (Sigle-Rushton and McLanahan, 2017). Considering that the majority of children remain to live with their mom after the divorce, father absence is quite usual. Thus, the rates of teen maternity among women whose daddies were lacking are greater, depending when in the women' life the separation took place. Furthermore, there is more proof of the impacts of father absence on early sexual activity and teen maternity than on various other behavior or psychological health issue. Hence, the separated mom daughter relationship is an important item of the challenge when it involves the impacts of divorce on teenage daughters. The trouble is exactly how can mothers in solitary parent family's post-divorce assistance to ensure the wellness of their adolescent children (Bastaits, Pasteels \& Mortelmans, 2018).

The effective effects of separation on teen little girls are lowered when parents work together. Regardless of the dissolution of their marriage, they are and will certainly constantly be parents. For that reason, they can take particular actions to construct the self-esteem of teen children and strengthen their sense of security. Teen little girls are specifically vulnerable to the effects of separation. However, separation is painful for everybody who is included. The problem is just how to lower the adverse effects of divorce on all members of the family. However, following a few of the steps laid out above might minimize the unfavorable influences. Ultimately, the goal is to shield teen little girls so that they can turn into resistant, healthy and balanced young people. Divorce completely breaks household and partnership between children and parents. It frequently causes devastating conflict management techniques, diminished social capability and for children, the very early loss of virginity, along with reduced feeling of masculinity or womanhood for young people. It also results in higher problems with dating, more common-law marriage, and higher possibility of separation, greater assumptions of separation later on in life, and a reduced desire to have youngsters. Separation results in disturbances in the parent-child relationship, continuing dissonance within former partners, loss of emotional assistance, economic hardship, and a rise in the number of various other unfavorable life events.

Children battle the most during the very first year or two after the separation. Children are most likely to experience distress, anger, anxiousness, and shock. Yet several children seem to recuperate. They get used to changes in their everyday routines and they grow comfy with their living arrangements. Others, nevertheless, never truly seem to go back to regular. These little portions of children might experience continuous possibly also long-lasting issues after their parents' separation.

https://doi.org/10.53819/81018102t5033 


\subsection{Literature Review}

Lansford (2020) conducted research to check on the impacts of separation amongst 16 pre-primary institutions, 55 primary schools and 3 secondary schools, where an example dimension of 10 was made use of for estimation, i.e., 2 pre-primary, 5 primary and 3 secondary schools. The research wished to find out ways in which pre- schoolers social growth at age nine and below are influenced by separation, to discover methods which children social growth at age 9-13 are impacted by separation, to determine methods which young adults are impacted by separation at age 15-25, and to develop methods which parents staying together influences the children's social growth. The research survey will certainly accumulate information via sets of questions that will certainly be directly administered by the scientist. The target population consisted of head-teachers, instructors and learners of pre-primary, main and secondary school since they were the people on the ground that experiences such impacts on their day-to-days live. A descriptive survey was utilized. The research discovered learners aged 0-9 years are influenced by separation and this is shared by them revealing distress and behavior issues both in learning institutions and at home. It is additionally discovered that separation influences the young people 15-25 years and this is revealed by the decisions that they make. The application of mediators programs, fostering of parenting education and learning can lower separation results on children' social growth within the separation process. It suggested that implementation of guidance and therapy to assist children understands and adapts to prevent lasting impacts of their parents' divorce.

Research by Anderson (2018) on evaluating the effect of household framework on the health and well-being of children discovered that children dealing with their married, biological parents constantly have better physical, psychological, and academic well-being. Doctors and society should promote the family members framework that has the very best opportunity of generating healthy and balanced children. The most effective clinical literary works to date recommends that, with the exception of parents faced with unresolvable marriage physical violence, youngsters make out better when parents operate at preserving the marriage. Consequently, society must strive to support healthy and balanced marriages and to prevent couples from divorcing.

A study by Ganong and Coleman (2017) in the acceleration of the divorce rate from the mid-1960s to the very early 1980s, the variety of nontraditional family members such as single-parent family members and reconstituted families have enhanced relative to intact, first-time extended families, the partnership between divorce, family make-up, and children' health. It was discovered that children's emotional adjustment, gender-role positioning, and antisocial behavior are impacted by family structure, whereas other dimensions of well-being are untouched. Yet the study suggests that these findings need to be analyzed with caution due to the methodological deficiencies of many of the researches on which these findings are based. Several variables, consisting of the level of household dispute, may be central variables mediating the impact of household structure on children. A study by Geir, Rodolfo and Ximing (2017) on the opportunity of separating the impacts of separation from selection when examining the impacts of parental separation on children's threat habits. They utilized propensity score matching and longitudinal information methods to approximate the impacts of parents' separation on their children's binge drinking, alcohol consumption, tobacco use, marijuana use, and narcotic use. The children were in between 12 and 18 years old in the very first study and between 18 and 24 years old in the second study. The outcomes recommend that adult separation considerably boosted the possibility of risk behaviors

\section{https://doi.org/10.53819/81018102t5033}


in their children. In addition, most of these adverse influences lingered gradually, specifically amongst teenage girls.

Moreover, a study conducted by Tullius, De Kroon, Almansa and Reijneveld (2021) discovered that adult divorce is just one of the most demanding life events for youth and is frequently related to durable psychological and behavior issues. Nevertheless, not much is understood about the timing of the introduction of these psychological and behavioral problems in teens about the moment of parental separation, and its longitudinal results. They assessed the timing of psychological and behavior troubles in teens of separation and its longitudinal impacts. They made use of the very first four waves of the Tracking Adolescent's Individual Lives Survey (TRAILS) cohort that consisted of 2230, 10-- 12 years' olds at baseline. Emotional and behavioral troubles were measured with the Youth Self-Report, as internalizing and externalizing issues. Multilevel evaluation was related to assess the impact of divorce on emotional and behavioral troubles. The degree of both internalizing and externalizing issues were considerably higher in the duration after parental separation but not in the duration prior to separation, with a relentless and rising result over the follow-up durations compared to teen's not experiencing separation. Adolescents often tend to create even more psychological and behavioral issues in the duration after parental divorce, not before. These impacts are durable and underscore the requirement for better take care of children with divorcing parents.

Leopold (2018) argued that separation is a commonality in today's family members; several children grow up in residences separated by divorce. The implications of divorce on the household framework can be ravaging and influence numerous areas of the adolescent's development. The teenage can encounter considerable challenges as the structure of their family member's changes because of separation. Along with the commonality of separation, it is also shown that mental health problems such as anxiousness and anxiety additionally exist in today's teens. With high varieties of children from divorced family members and high variety of teens experiencing psychological health problems, today's teachers and mental health specialists require to be knowledgeable about the dangers and protective elements to properly assist these adolescents resolve solid feelings connected to divorce and deal with mental health conditions. The school setting can supply learners with an outlet in which to share sensations and discover brand-new abilities to manage strong emotions. It is essential that today's instructors to be knowledgeable about such programs to assist the high variety of children having problem with these concerns.

Galluzzo (2012) sought to examine the academic and social influence of separation on early childhood year's learners in learning institution. The research was anchored on 3 locations of past study: Just how do early youth teachers, counselors, psycho therapist, registered nurses, principals and assistant principals explain their experience of collaborating with youngsters of ages Preschool to Grade 1 who have experienced adult separation as contrasted to children that do not experience separation; In what means does separation impact very early childhood years learners" academic accomplishment and actions in institution and approaches and programs would early childhood instructors, counselors, psychologist, registered nurses, principals and assistant principals like to see established at institution to assist sustain these learners and their parents. Individuals consisted of 20 early childhood teachers and 5 administrators in the Boston, Massachusetts location that finished open ended sets of questions in a focus group atmosphere and interview questions. The positive and unfavorable impacts of separation in school for very early

\section{https://doi.org/10.53819/81018102t5033}


youth learners. It was exposed that separation adversely impacted early childhood learners' actions and academics performance. Nonetheless, the level to which separation influenced the kid was dependent on just how the parents and child responded and responded since every divorce scenario is different. There were numerous approaches teachers revealed that they were making use of in the past to assist learners cope in the class. Tips for additional treatments for managers to take on were additionally stated such as parent education workshops and lunch bunch teams.

According to a statistical study by Bumpass and Lu (2020) $40 \%$ of children that stay in the USA experienced parental divorce prior they reach the age of 18. Consequently, lots of children were impacted by the process of divorce and its completion. When my daughter was just 9 years of ages, she asked incredulously why my hubby and I were the only married couple in our community. After twenty-two years of marital relationship, I recognized long-lasting marriages in my area are not standard. When parents' separation, children often encounter the loss of one parent continuous visibility and economic security; as a result, tension might take an incredible toll on the youngsters. Although independently these consequences are substantial, they do not deal with the kid's academic and social life, or their viewpoint on what a healthy and balanced partnership may look like. Even more, a kid's age may play a considerable duty in divorce. It suggested that while older children have a tendency to endure when parents' separation, younger children, in most cases, endure extra. The checked out brief and lasting changes of children that go through their parents' divorce and the certain behavior troubles that might feature the dissolution of their parents' marital relationship.

Kreidl, Štípková and Hubatková (2017) performed a research on the long-lasting effects of adult divorce in a relative perspective. Unique focus was paid to the heterogeneity of the repercussions of separation for children's educational accomplishment by parental education. The research tried to develop whether the parental separation charge for tertiary education accomplishment differs by socioeconomic history, and whether it relies on the societal context. Information was drawn from the initial wave of the Generations and Gender Survey, covering 14 nations. They approximated multi-level random-slope designs for the conclusion of tertiary education. The outcomes showed that adult separation is adversely associated with youngsters' tertiary education attainment. Across 14 countries considered in the research, youngsters of apart parents had a chance of accomplishing a university degree that is on ordinary 7 percentage points less than that of children from intact family members. The break up penalty is stronger for youngsters of very educated parents, and is independent of the level of diffusion of divorce. In countries with early choice right into educational tracks, separation appears to have more unfavorable repercussions for the youngsters of improperly educated mothers. For children in most nations, adult separation is connected with a lower probability of acquiring a university degree. The divorce penalty is larger for children with extremely enlightened parents. This equalizing pattern is emphasized in countries with a thorough educational system.

Though study revealed that separation is stressful for children of any type of age, there are some disparities in the impact of separation, relying on the age of the kid at separation (Amato, 2018). Study reveals that children that are really young when they experience their parents' separation approximately about age 6 tend to fare much better, long-term, than older children. Short-term is another tale. In the Wallerstein separated youngsters younger children appeared to have even more signs of depression and psychological scarring than their older siblings immediately after the

\section{https://doi.org/10.53819/81018102t5033}


separation. But 10 years later, these more youthful youngsters were much more well-adjusted and much less strained by vivid memories of their parents' problem than the older brother or sisters. The majority of children are resilient and does not exhibit emotional issues. Nevertheless, even if your kid is not showing signs of major mental disorder, they might still be battling. Children whose parents are separated go through a variety of emotions, and sometimes those can manifest in some usual disruptions in their life (Lansford, 2020). Common effects of separation on children consist of: Schooling troubles, such as bad performance, behavior issues at school, defiance and noncompliance, depression, problem forming intimate partnerships, boosted anxiety, sadness or anger at one parent or both, obstacles in quadrating with siblings, peers, and parents and difficulty to sleep.

\subsection{Research Findings and Conclusion}

The study found that parental divorce affects the children's educational attainment in united states of America negatively. Divorce and separation correlate positively with diminished school achievement and performance. Children whose parents are separated go through a wide range of feelings, occasionally those can show up in some common disruptions in their life. The degree of problem before and after a separation likewise affects whether or not the children will certainly deal with long or short-term psychological health problems. Children of separated parents experience self-protective concern and an unwillingness to become part of a fully committed relationship. Children are more likely to manage the results of divorce by engaging in high-risk actions. Drug use and early sexual activity are a lot more common amongst children of divorce than their peers. Separations that involve heavy adult conflict are usually the ones that impact children most negatively. Parental divorce dramatically boosts the probability of risky behaviors in their children. Additionally, most of these adverse influences continued gradually, particularly amongst teenage girls. Moreover, children who experience parents' separation can be impacted well right into their adulthood. Some youngsters are resilient and don't exhibit emotional problems. Teens whose parents are separated experience a vast array of emotions, and occasionally those can manifest in some typical disruptions in their life. For school going learners the educators exposed that they were making use of different strategies to assist the learners deal in the classroom and concentrate with their studies, while in other studies parental separation is connected with a reduced likelihood of achieving a university level. Kid's age might play a significant role in divorce; it was found that older children tend to suffer most when parents' separate, more youthful children, in most cases. There are both favorable and negative results of divorce in school for early childhood learners. It was disclosed that separation negatively influenced very early childhood year's students' actions and academics performance.

The study concluded that parental separation/divorce is related to children's educational attainment negatively. Children from divorced families may experience more externalizing problems, such as conduct disorders, delinquency, and impulsive behavior than kids from two-parent families. In addition to increased behavior problems, children may also experience more conflict with peers after a divorce. Divorce and separation reduce children's likelihood of attending college. Furthermore, students who have already completed secondary school but who have experienced their parents' divorce graduate from college, compared to 40 percent among their peers from intact families. Over 57 percent of children who live in intact biological families enter college, compared to 32.5 percent of children in stepfamilies, 47.5 percent of children in single-parent families. It is

\section{https://doi.org/10.53819/81018102t5033}


concluded that parental divorce has a greater impact on likelihood to complete secondary school than college and children from intact married families have the highest high school graduation rate and are more likely to gain more education after graduating from high school than those from other family structures.

\subsection{Recommendations}

The study recommended that divorce should be discouraged, especially for couples with children. If divorce is the only way to go, the parents need to develop a mechanism to enable the children to continue with everyday life. Since divorce is so prevalent worldwide, it is critical to understand its impact on children and establish ways to protect them from its potentially damaging effects. The family living together raises children who are more innovative and hardworking due to the exposure from their parents. The research suggested that although separation will undoubtedly be difficult for everybody in the family, divorced parents must do their best to be with children even after the divorce. It is recommended that divorced parents should establish ways that will increase the happiness of their children. The best thing parents can do is let their kids know that any emotions they have are okay. Divorced parents should always be ready to help the children when a need occurs. The government should develop policies that will ensure children from divorced families live happy life. The parents should be responsible for the upkeep of the children.

\section{REFERENCES}

Amato, P. R. (2018). Life-span adjustment of children to their parents' divorce. Journal of The future of children, 143-164. https://doi.org/10.2307/1602482

Anderson, J. (2018). The impact of family structure on the health of children: Journal of Effects of $\begin{array}{llll}\text { divorce. } & \text { The } & \text { 2inacre } & \text { Quarterly, }\end{array}$ https://doi.org/10.1179/0024363914Z.00000000087

Bastaits, K., Pasteels, I., \& Mortelmans, D. (2018). How do post-divorce paternal and maternal family trajectories relate to adolescents' subjective well-being?. Journal of adolescence, 64, 98-108. https://doi.org/10.1016/j.adolescence.2018.02.005

Bryner, C. L. (2021). Children of divorce. The Journal of the American Board of Family Practice, 14(3), 201-210.

Bumpass, L., \& Lu, H. H. (2020). Trends in cohabitation and implications for children s family contexts in the United States. International Journal of Population studies, 54(1), 29-41. https://doi.org/10.1080/713779060

Galluzzo, D. M. (2012). The academic and social impact of divorce on early childhood students in school (Doctoral dissertation, Northeastern University).

Ganong, L. H., \& Coleman, M. (2017). Stepfamily relationships. Springer-Verlag New York. https://doi.org/10.1007/978-1-4899-7702-1

Goodman, M., Bonds, D., Sandler, I., \& Braver, S. (2019). Parent psychoeducational programs and reducing the negative effects of interparental conflict following divorce. Family Court Review, 42(2), 263-279. https://doi.org/10.1111/j.174-1617.2004.tb00648.x

\section{https://doi.org/10.53819/81018102t5033}


Kreidl, M., Štípková, M., \& Hubatková, B. (2017). Parental separation and children's education in a comparative perspective: Does the burden disappear when separation is more common?. Demographic Research, 36, 73-110. https://doi.org/10.4054/DemRes.2017.36.3

Lansford, J. E. (2020). Parental divorce and children's adjustment. Journal of Perspectives on psychological science, 4(2), 140-152. https://doi.org/10.1111/j.1745-6924.2009.01114.x

Leopold, T. (2018). Gender differences in the consequences of divorce: A study of multiple outcomes. Demography, 55(3), 769-797. https://doi.org/10.1007/s13524-018-0667-6

Mechanic, D., \& Hansell, S. (2021). Divorce, family conflict, and adolescents' well-being. Journal of Health and Social Behavior, 105-116. https://doi.org/10.2307/2136916

Rohrbaugh, J. B. (2020). Domestic violence in same-gender relationships. Family court review, 44(2), 287-299. https://doi.org/10.1111/j.1744-1617.2006.00086.X

Sanders, M. R., Halford, W. K., \& Behrens, B. C. (2018). Parental divorce and premarital couple communication. Journal of Family Psychology, 13(1), 60. https://doi.org/10.1037/0893$\underline{3200 \cdot 13.1 .60}$

Seeman, H. (2018). Adolescents' coping after parental divorce: Depression, high-risk behaviors, and suicidality. University of California, Los Angeles.

Sigle-Rushton, W., \& McLanahan, S. (2017). Father absence and child well-being: A critical review. Journal of the future of the family, 116, 120-122.

Thiong'o, E. K. (2016). The effects of divorce on children's social development (Doctoral dissertation, University of Nairobi).

Tullius, J. M., De Kroon, M. L., Almansa, J., \& Reijneveld, S. A. (2021). Adolescents' mental health problems increase after parental divorce, not before, and persist until adulthood: a longitudinal TRAILS study. Journal of European Child \& Adolescent Psychiatry, 1-10. https://doi.org/10.1007/s00787-020-01715-0

Waggoner, L. W. (2019). With Marriage on the Decline and Cohabitation on the Rise, What About Marital Rights for Unmarried Partners. ACTEC LJ, 41, 49.

Zartler, U. (2019). Reassembling families after divorce. In Families and Kinship in Contemporary Europe (pp. 178-191). Palgrave Macmillan, London. https://doi.org/10.1057/9780230307452_12 